\title{
Cyanoarylporphyrazines with High Viscosity Sensitivity: A Step towards Dosimetry-Assisted Photodynamic Cancer Treatment
}

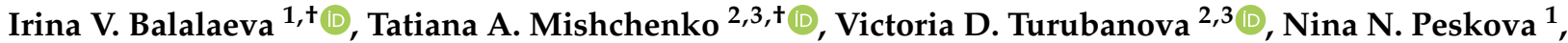 \\ Natalia Y. Shilyagina ${ }^{1}$, Vladimir I. Plekhanov ${ }^{4}{ }^{\mathbb{D}}$, Svetlana A. Lermontova ${ }^{5}$, Larisa G. Klapshina ${ }^{5, \ddagger}$, \\ Maria V. Vedunova $2,3, \ddagger(\mathbb{D}$ and Dmitri V. Krysko $3,6,7,8, *, \ddagger \mathbb{D}$
}

1 Department of Biophysics, Institute of Biology and Biomedicine, Lobachevsky State University of Nizhny Novgorod, 23 Gagarin ave., 603022 Nizhny Novgorod, Russia; irin-b@mail.ru (I.V.B.);

nin-22@yandex.ru (N.N.P.); nat-lekanova@yandex.ru (N.Y.S.)

2 Department of Neurotechnology, Institute of Biology and Biomedicine, Lobachevsky State University of Nizhny Novgorod, 23 Gagarin ave., 603022 Nizhny Novgorod, Russia; saHarnova87@mail.ru (T.A.M.); vikaturu@mail.ru (V.D.T.); MVedunova@yandex.ru (M.V.V.)

3 Department of Basic and Medical Genetics, Institute of Biology and Biomedicine, Lobachevsky State University of Nizhny Novgorod, 23 Gagarin ave., 603022 Nizhny Novgorod, Russia

4 Department of Radiophysical Methods in Medicine, Federal Research Center Institute of Applied Physics of the Russian Academy of Sciences, 46 Ul'yanov Street, 603950 Nizhny Novgorod, Russia;

Citation: Balalaeva, I.V.; Mishchenko, T.A.; Turubanova, V.D.; Peskova, N.N.; Shilyagina, N.Y.; Plekhanov, V.I.; Lermontova, S.A.; Klapshina, L.G.; Vedunova, M.V.; Krysko, D.V. Cyanoarylporphyrazines with High Viscosity Sensitivity: A Step towards Dosimetry-Assisted Photodynamic Cancer Treatment. Molecules 2021, 26, 5816. https://doi.org/10.3390/ molecules26195816

Academic Editor: Már Másson

Received: 13 July 2021

Accepted: 22 September 2021

Published: 25 September 2021

Publisher's Note: MDPI stays neutra with regard to jurisdictional claims in published maps and institutional affiliations.

Copyright: (C) 2021 by the authors Licensee MDPI, Basel, Switzerland This article is an open access article distributed under the terms and conditions of the Creative Commons Attribution (CC BY) license (https:// creativecommons.org/licenses/by/ $4.0 /)$.
Plehanov_VI@mail.ru

5 Sector of Chromophors for Medicine, G.A. Razuvaev Institute of Organometallic Chemistry of the Russian Academy of Sciences, 49 Tropinin st., 603137 Nizhny Novgorod, Russia; lermontovasa@rambler.ru (S.A.L.); klarisa@ioms.ras.ru (L.G.K.)

6 Cell Death Investigation and Therapy Laboratory (CDIT), Anatomy and Embryology Unit, Department of Human Structure and Repair, Ghent University, C. Heymanslaan 10, Building B3, 4th Floor, 9000 Ghent, Belgium

7 Cancer Research Institute Ghent, 9000 Ghent, Belgium

8 Department of Pathophysiology, Sechenov First Moscow State Medical University (Sechenov University), 8-2 Trubetskaya st., 119991 Moscow, Russia

* Correspondence: dmitri.krysko@ugent.be; Tel.: +32-9-332-3396

+ Authors are joint first authors.

$\ddagger$ Authors are joint senior authors.

Abstract: Despite the significant relevance of photodynamic therapy (PDT) as an efficient strategy for primary and adjuvant anticancer treatment, several challenges compromise its efficiency. In order to develop an "ideal photosensitizer" and the requirements applied to photosensitizers for PDT, there is still a need for new photodynamic agents with improved photophysical and photobiological properties. In this study, we performed a detailed characterization of two tetracyanotetra(aryl)porphyrazine dyes with 4-biphenyl (pz II) and 4-diethylaminophenyl (pz IV) groups in the periphery of the porphyrazine macrocycle. Photophysical properties, namely, fluorescence quantum yield and lifetime of both photosensitizers, demonstrate extremely high dependence on the viscosity of the environment, which enables them to be used as viscosity sensors. Pz II and pz IV easily enter cancer cells and efficiently induce cell death under light irradiation. Using fluorescence lifetime imaging microscopy, we demonstrated the possibility of assessing local intracellular viscosity and visualizing viscosity changes driven by PDT treatment with the compounds. Thus, pz II and pz IV combine the features of potent photodynamic agents and viscosity sensors. These data suggest that the unique properties of the compounds provide a tool for PDT dosimetry and tailoring the PDT treatment regimen to the individual characteristics of each patient.

Keywords: photodynamic therapy; cancer treatment; photosensitizers; porphyrazines; intracellular viscosity; fluorescent molecular rotors; cell death 


\section{Introduction}

The past decade has witnessed major breakthroughs in photodynamic therapy (PDT) as an efficient strategy for primary and adjuvant anticancer treatment. PDT is a clinically approved minimally invasive procedure based on a photodynamic agent's local or systemic administration (photosensitizer) with subsequent selective accumulation in tumor tissue and excitation by irradiation with visible light of appropriate wavelength. The excited photosensitizer reacts with cellular oxygen, resulting in the generation of cytotoxic reactive oxygen species (e.g., singlet oxygen $\left({ }^{1} \mathrm{O}_{2}\right)$, superoxide anion $\left(\mathrm{O}_{2}{ }^{-\bullet}\right)$, hydroperoxide radical $\left(\mathrm{HOO}^{\bullet}\right)$, peroxides $\left(\mathrm{H}_{2} \mathrm{O}_{2}, \mathrm{ROOH}\right)$, and hydroxyl radical $\left.\left(\mathrm{HO}^{\bullet}\right)\right)$, and initiating molecular mechanisms which lead to tumor tissue destruction and vascular damage [1-3]. The efficient development of photodynamic reaction depends primarily on the photophysical and photochemical properties of the photosensitizer [4-6], its tissue distribution $[7,8]$, its uptake by cancer cells and subcellular localization [4,9-11], and the irradiation dose [12,13].

Despite significant progress in PDT, there are still several challenges that compromise its efficiency. For instance, oxygen deficiency (hypoxia) in the tumor microenvironment can significantly diminish PDT efficiency for solid tumors $[1,14,15]$. Insufficient selectivity of the photosensitizer to the tumor and its accumulation in normal organs and tissues, especially skin and eyes, lead to undesirable photoinduced side effects $[8,16,17]$. Moreover, several types of tumors often become resistant to apoptotic and necroptotic cell death modalities, making their induction by PDT no longer an option [18,19]. Therefore, there is still a need for new photosensitizers with improved photodynamic properties and less cytotoxic effects for normal tissues.

We recently reported the novel group of tetracyanotetra(aryl)porphyrazines (hereinafter, $\mathbf{p z}$ ) as prospective photosensitizers for PDT [20-24]. The structure of $\mathbf{p z}$ determines their unique photophysical properties; namely, an ability to induce the production of strongly cytotoxic singlet oxygen combined with high viscosity sensitivity of the fluorescence parameters [20]. This can be explained by the fact that pz belongs to the molecular rotors: excitation of this type of molecule due to light absorption leads to charge transfer followed by intramolecular rotation. This results in a high rate of non-radiative relaxation of the excited state of the molecular rotor. In viscous media, the rotating is inhibited, resulting in a drastic increase in fluorescence intensity and fluorescence lifetime. We should underline that modification of the peripheral aryl groups coupled with a macrocycle core can significantly affect the photophysical and cytotoxic properties of $\mathbf{p z}$, thus opening new prospects for fine-tuning of $\mathbf{p z}$ as an effective tool for PDT treatment [21-24].

Moreover, in our previous study, we showed that several compounds of $\mathbf{p z}$ group (pz I-IV) can be considered as candidate photosensitizers for PDT treatment of glioma [25]. Of note, the special requirement for brain tumors is the minimal impact of photosensitizers on neurons functioning. The lowest neuronal toxicity was obtained for $\mathbf{p z}$ with four 4-biphenyl groups in the aryl frame of the macrocycle (pz II). Mild toxicity was detected for compound with 4-diethylaminophenyl groups (pz IV).

In this study, we performed a detailed characterization of pz II and pz IV in terms of photophysical and photobiological properties, aiming at their future PDT application. Herein, we provided data on photophysical properties of photosensitizers, their viscosity sensitivity, as well as accumulation dynamics and subcellular distribution in cancer cells. Finally, we performed a comparative analysis of the photodynamic properties of $\mathbf{p z}$ II and pz IV for two cancer cell lines of different origin (murine glioma GL261 and human epidermoid carcinoma A431). Using fluorescence lifetime imaging microscopy (FLIM), we demonstrated the possibility of assessing local intracellular viscosity using pz II and pz IV as viscosity sensors and tracking the viscosity changes driven by PDT treatment. We assume that measuring the fluorescence lifetime of the tested compounds reflects the physiological states of the cells and can provide a tool for PDT dosimetry and tailor the PDT treatment regimen to the individual characteristics of each patient. 


\section{Results}

\subsection{Photophysical Properties of $p z$ II and $p z I V$}

Two tetracyanotetra(aryl)porphyrazine dyes were tested with 4-biphenyl (pz II) and 4-diethylaminophenyl (pz IV) groups in the periphery of the porphyrazine macrocycle. For the synthesis of $\mathbf{p z}$ II and $\mathbf{p z} \mathbf{~ I V}$, we used a synthetic approach using a metal template assembly of the porphyrazine frameworks that we developed and described in detail previously $[20,21,26]$. The chemical structure of the dyes is shown in Figure 1.

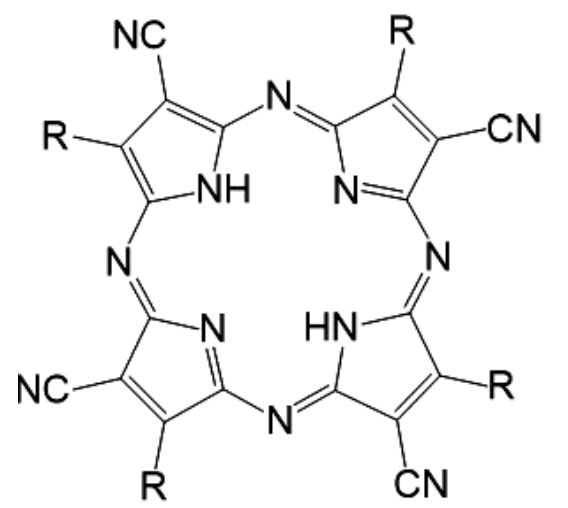<smiles>[R]#Cc1ccc(-c2ccccc2)cc1</smiles>

Figure 1. A chemical structure of the synthesized cyanoarylporphyrazines: pz II and pz IV.

Both of the compounds demonstrated intensive light absorption, with a maximum in the red spectral region at 592-594 nm (Q-band) and a molar extinction coefficient exceeding $10^{4}$ (Table 1). In a water solution, the fluorescence of both of the compounds was rather weak, with quantum yields of about 0.001-0.002. The fluorescence peak of $\mathbf{p z}$ II has a slight bathochromic shift compared to pz IV due to the extension of the $\pi$-conjugated aromatic system (Table 1).

Table 1. Photophysical properties of pz II and pz IV in a water solution.

\begin{tabular}{ccccc}
\hline Porphyrazine & $\boldsymbol{\lambda}_{\text {abs }}, \mathbf{n m}$ & $\varepsilon$ & $\lambda_{\mathrm{em}}, \mathbf{n m}$ & $\boldsymbol{\varphi}$ \\
\hline pz II & 594 & $5.3 \times 10^{4}$ & 654 & 0.001 \\
pz IV & 592 & $1.8 \times 10^{4}$ & 650 & 0.002 \\
\hline
\end{tabular}

$\lambda_{\text {abs, }}$ maxima of absorption spectra; $\lambda_{\text {em }}$, maxima of fluorescence spectra; $\varepsilon$, molar extinction coefficient $\left(\mathrm{L} \times \mathrm{mol}^{-1} \times \mathrm{cm}^{-1}\right) ; \varphi$, quantum yield.

To investigate whether the photophysical properties of pz II and pz IV depend on viscosity, we analyzed their fluorescence spectra in ethanol-glycerol solutions with a glycerol volume concentration from 20 to $100 \%$. The viscosities of the corresponding solutions at room temperature varied from 3.9 to $820 \mathrm{cP}$. No broadening or spectral shift was observed (Figure 2), which would indicate aggregation. However, fluorescence intensity (i.e., fluorescence quantum yield) demonstrated an increase of more than two orders of magnitude in viscous media; the quantum yield values in glycerol were 0.23 and 0.60 for pz II and pz IV, respectively.

Note that there is a difference in the photostability of the two compounds (Figure 3 and Figure S1 from Supplementary Materials). While pz IV in media with a viscosity of $30 \mathrm{cP}$ demonstrated rapid photobleaching under irradiation with power density of $20 \mathrm{~mW} / \mathrm{cm}^{2}$, pz II was much more stable, assuming a higher contribution of excited state relaxation through intramolecular rotation. 


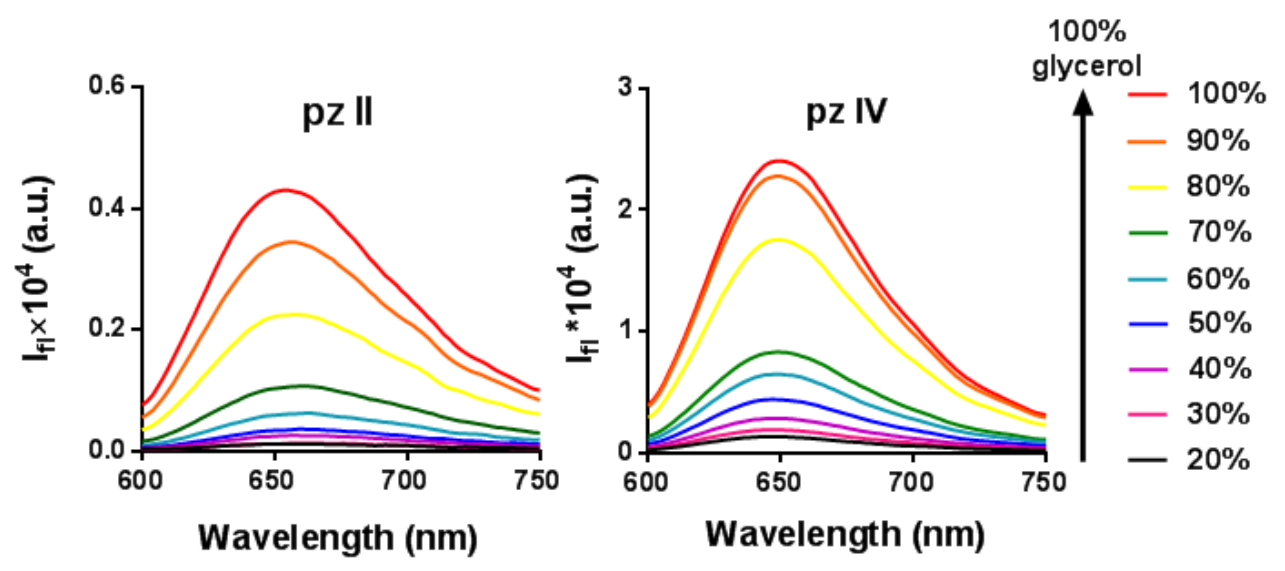

Figure 2. Enhancement of the fluorescence intensity of pz II and pz IV in ethanol-glycerol solutions at room temperature.

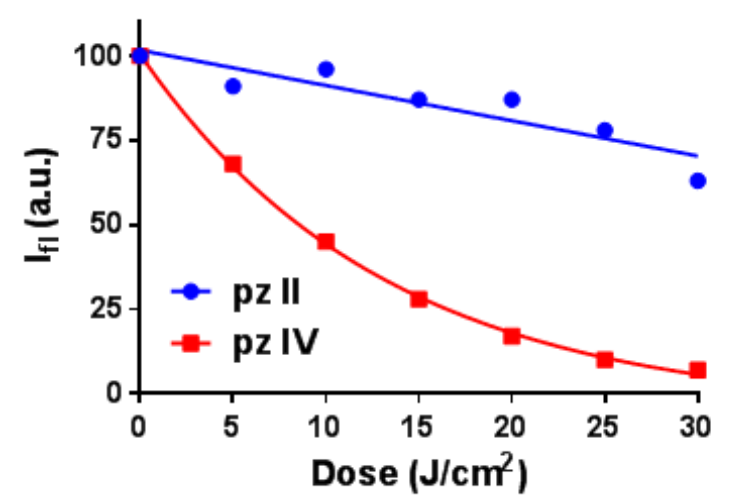

Figure 3. Photobleaching of pz II and pz IV in ethanol-glycerol solutions with a viscosity of $30 \mathrm{cP}$ induced by irradiation with power density $20 \mathrm{~mW} / \mathrm{cm}^{2}$.

The fluorescence quantum yield's $\varphi$ dependence on the medium viscosity $\eta$ followed the well-known Förster-Hoffmann equation for fluorescent molecular rotors [27]:

$$
\lg (\varphi)=\mathrm{z}+\alpha \lg (\eta)
$$

where $\mathrm{z}$ and $\alpha$ are constants.

The coefficient $\alpha$ reflects the viscosity sensitivity and is 0.81 and 0.65 for $\mathbf{p z}$ II and pz IV, respectively (Figure 4). Such high viscosity dependence coefficients are characteristic of fluorescence molecular rotors [28,29].
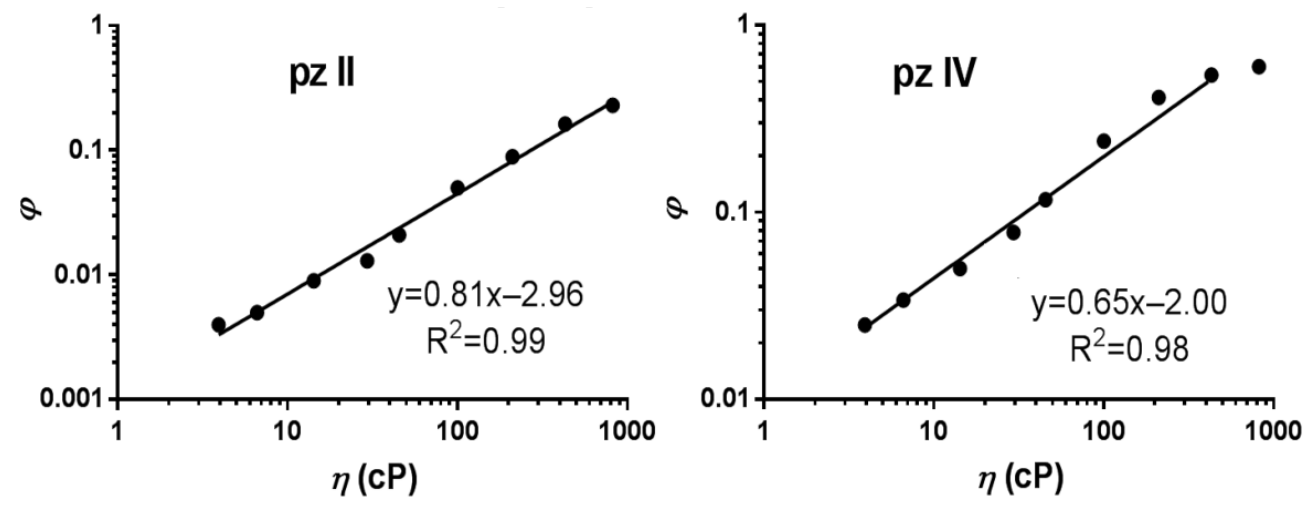

Figure 4. Dependence of the fluorescence quantum yield $(\varphi)$ of $\mathbf{p z}$ II and pz IV on the viscosity $(\eta)$ measured in ethanol-glycerol solutions. The data followed the Förster-Hoffmann equation with coefficients of viscosity sensitivity of 0.81 and 0.65 , respectively. 
The similar dependence was registered for fluorescence lifetime (Figure 5 and Figure S2 from Supplementary Materials). The averaged lifetime $\tau_{a v}$ dependence on the medium viscosity can be described as:

$$
\lg \left(\tau_{a v}\right)=\lg \left(z / k_{r}\right)+\alpha \lg (\eta)
$$

where $k_{r}$ is the constant of radiative relaxation.
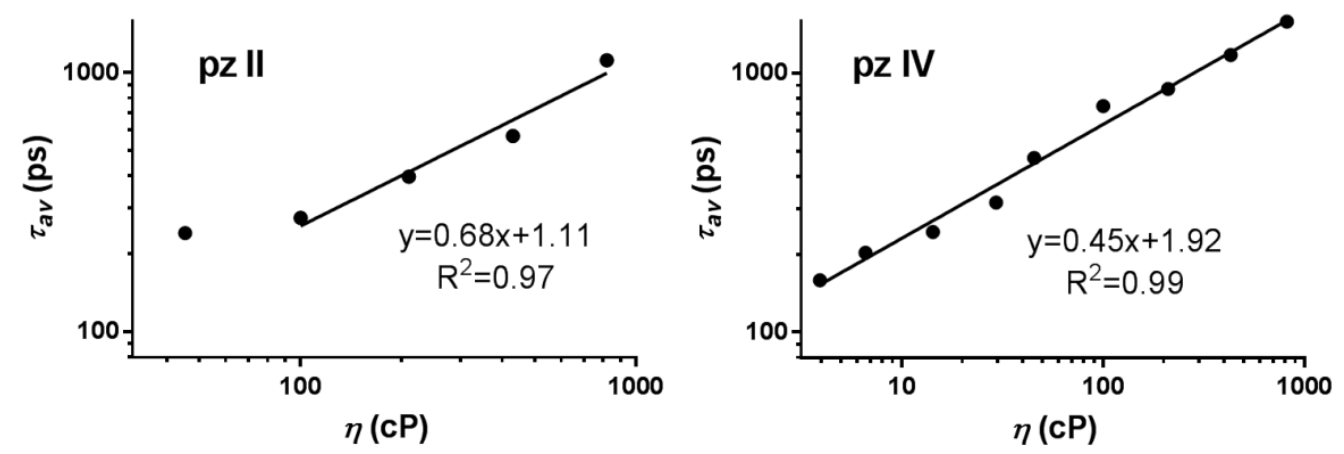

Figure 5. Dependence of the fluorescence lifetime of pz II and pz IV on the viscosity measured in ethanol-glycerol solutions. The data followed the Förster-Hoffmann equation with coefficients of viscosity sensitivity of 0.68 and 0.45 , respectively.

Of note, there is a difference in the properties of the two studied compounds. Due to technical limitations, we were not able to relevantly measure lifetimes lower than $200 \mathrm{ps}$. For $\mathbf{p z}$ II, the fluorescence lifetimes were very short in media with a viscosity of up to $100 \mathrm{cP}$ (Figure 5); this is in line with the lower values of quantum yield for this compound (Figure 4). Thus, we registered the viscosity dependence for pz II in 100-850 cP range. On the contrary, pz IV has a high fluorescence lifetime and quantum yield in the entirety of the analyzed viscosity range. At the same time, the coefficient of viscosity sensitivity was higher for pz II: 0.68 compared to 0.45 for $\mathbf{p z ~ I V}$ when measuring fluorescence lifetime.

Based on the performed measurements, we calculated the rate constants of radiative $k_{r}$ and non-radiative $k_{n r}$ relaxation (Figure 6). For both compounds, $k_{r}$ remained virtually unchanged in media with increasing viscosity; however, $k_{n r}$ drastically decreased. This proves the hypothesis that the rise in fluorescence quantum yield and lifetime of $\mathbf{p z}$ II and pz IV in viscous media resulted precisely from the limitation of non-radiative processes. The difference in the behavior of the two dyes is most clearly manifested in the rate constants' dependence on viscosity (Figure 6): the higher constant of non-radiative relaxation for $\mathbf{p z ~ I I , ~ d e m o n s t r a t i n g ~ i t s ~ p r e v a i l i n g ~ r o l e ~ i n ~ p z ~ I I ~ r e l a x a t i o n ~ i n ~ t h e ~ s t u d i e d ~ v i s c o s i t y ~ r a n g e , ~}$ and the higher sensitivity of $\mathbf{p z}$ IV to viscosity changes in low viscous media.

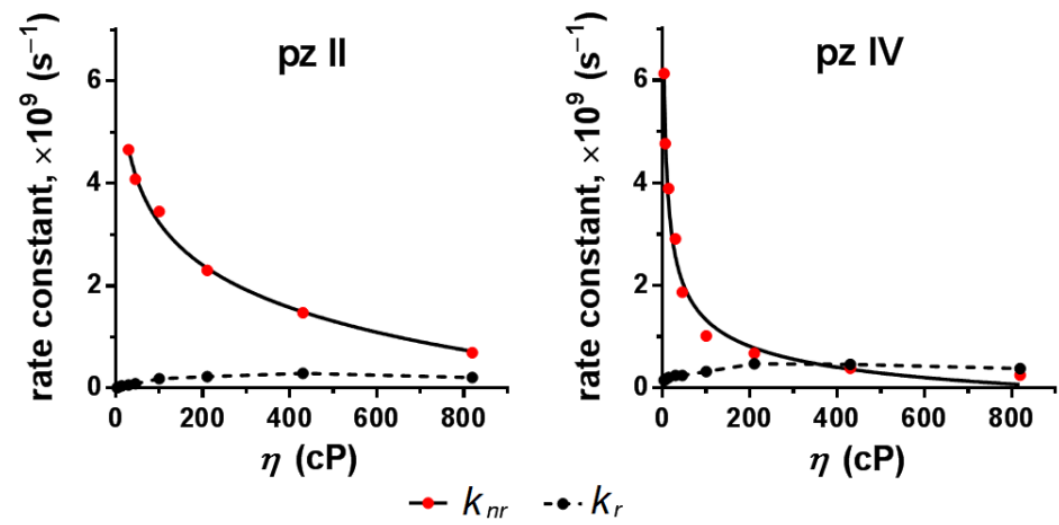

Figure 6. Dependence of constants of radiative $\left(k_{r}\right)$ and non-radiative $\left(k_{n r}\right)$ relaxation of $\mathbf{p z ~ I I ~ a n d ~}$ pz IV on the viscosity. 
Thus, pz II and pz IV demonstrate high viscosity sensitivity in solution, presumably due to belonging to the molecular rotors; both the quantum yield and fluorescence lifetime of the compounds can be measured for viscosity sensing purposes.

\subsection{Cellular Uptake and Photodynamic Properties of $p z$ II and $p z I V$}

To test the photobiological properties of pz II and pz IV, we used two cancer cell lines, murine glioma GL261 and human epidermoid carcinoma A431, and a line of immortalized human keratinocytes HaCaT. The choice of cancer lines was determined by the cells' origin from the tumors that are acceptable for PDT treatment. Both compounds were taken up by the cells; however, the rate of cellular uptake is significantly differed (Figure 7). Comparing the cell lines, the most intensive fluorescence signal in confocal images was obtained in glioma GL261 cells; the least intensive was found in carcinoma A431 cells.

(a)
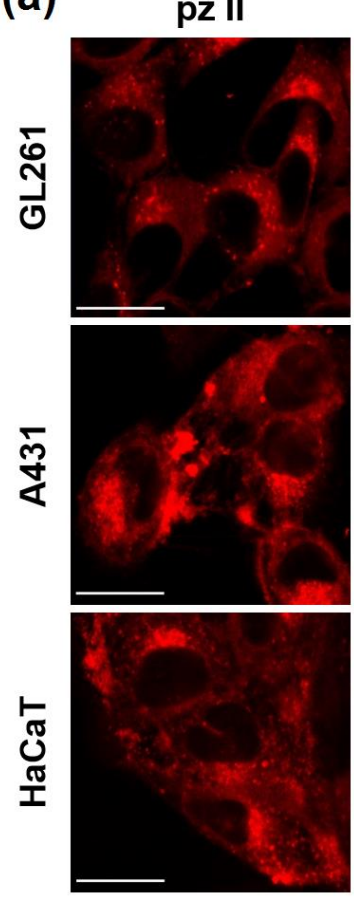
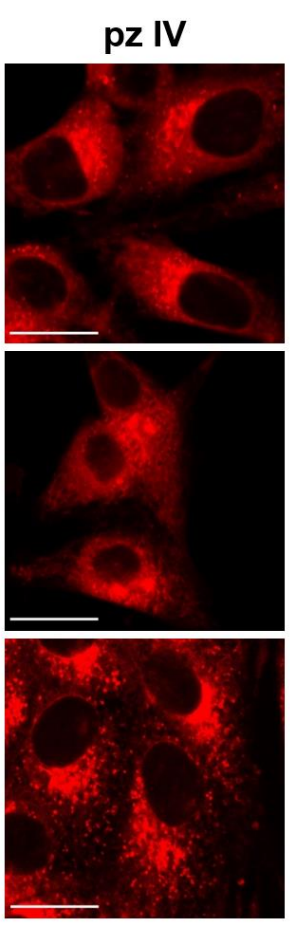
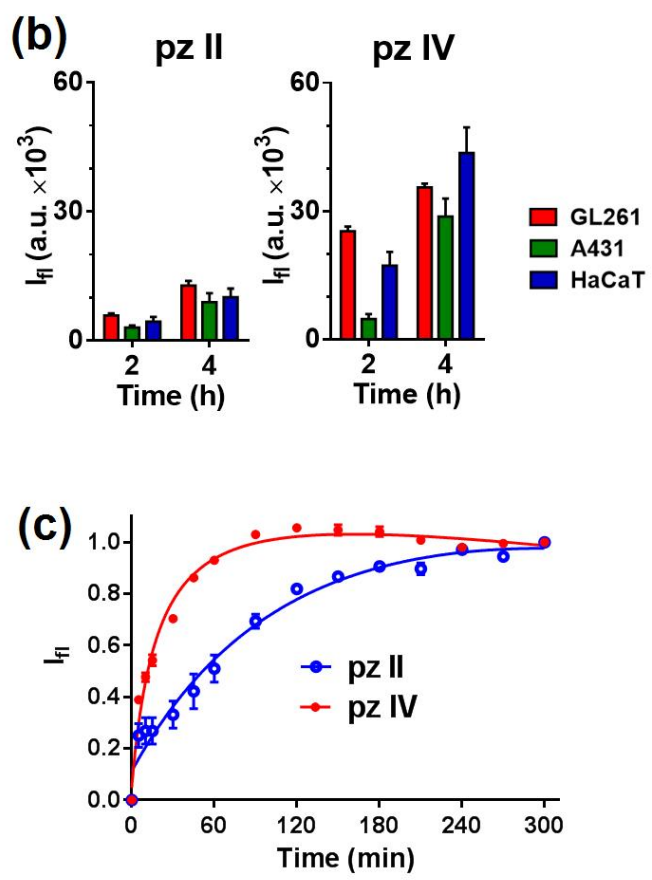

Figure 7. Analysis of the cellular uptake of pz II and pz IV. (a) Representative confocal images of murine glioma GL261, human epidermoid carcinoma A431, and human keratinocytes HaCaT cells after $240 \mathrm{~min}$ of incubation with the pz $(10 \mu \mathrm{M})$. Scale bar, $20 \mu \mathrm{m}$. (b) Relative accumulation of the pz by cells of different lines after 2 and $4 \mathrm{~h}$ incubation, estimated from confocal microscopy experiment $(\mathrm{n} \geq 10)$. (c) Dynamics of $\mathbf{p z}$ II and pz IV's accumulation in A431 cells. The pz was added to the culture medium at a concentration of $5 \mu \mathrm{M}$, and a plate reader repeatedly measured the fluorescence in the well of the plate with the cell culture. The signal growth results from pz entering the intracellular environment with a higher local viscosity compared to outer culture medium.

It should be noted that the unique photophysical properties of $\mathbf{p z}$ allowed us to apply an original measuring technique using continuous registering of the fluorescence of the cell culture in a multiwall plate with a plate reader. pz II and pz IV were added in the incubation media; virtually no fluorescence signal was detected in the media itself due to its low viscosity. When entering the cell, the pz enters a much more viscous environment, leading to significant enhancement of the detected fluorescence signal. The molecule of pz II with larger aryl radicals resulted in relatively slow uptake and reaching maximal signal in about $3-4 \mathrm{~h}$ (Figure $7 \mathrm{~b}, \mathrm{c}$ ). In the case of pz IV, $1.5 \mathrm{~h}$ was enough to reach the saturation level of the fluorescence. 
Predominant pz II and pz IV localize in both glioma GL261 and carcinoma A431 cells in the endoplasmic reticulum (ER) and Golgi apparatus (Figure 8). This is in accordance with the amphiphilic properties of the compounds. Of note, we previously reported that in murine neurons, both dyes were mostly held in vesicles with partial localization of pz II in ER [25]. Thus, the origin and properties of the cancer cells can influence the intracellular distribution of $\mathbf{p z}$.

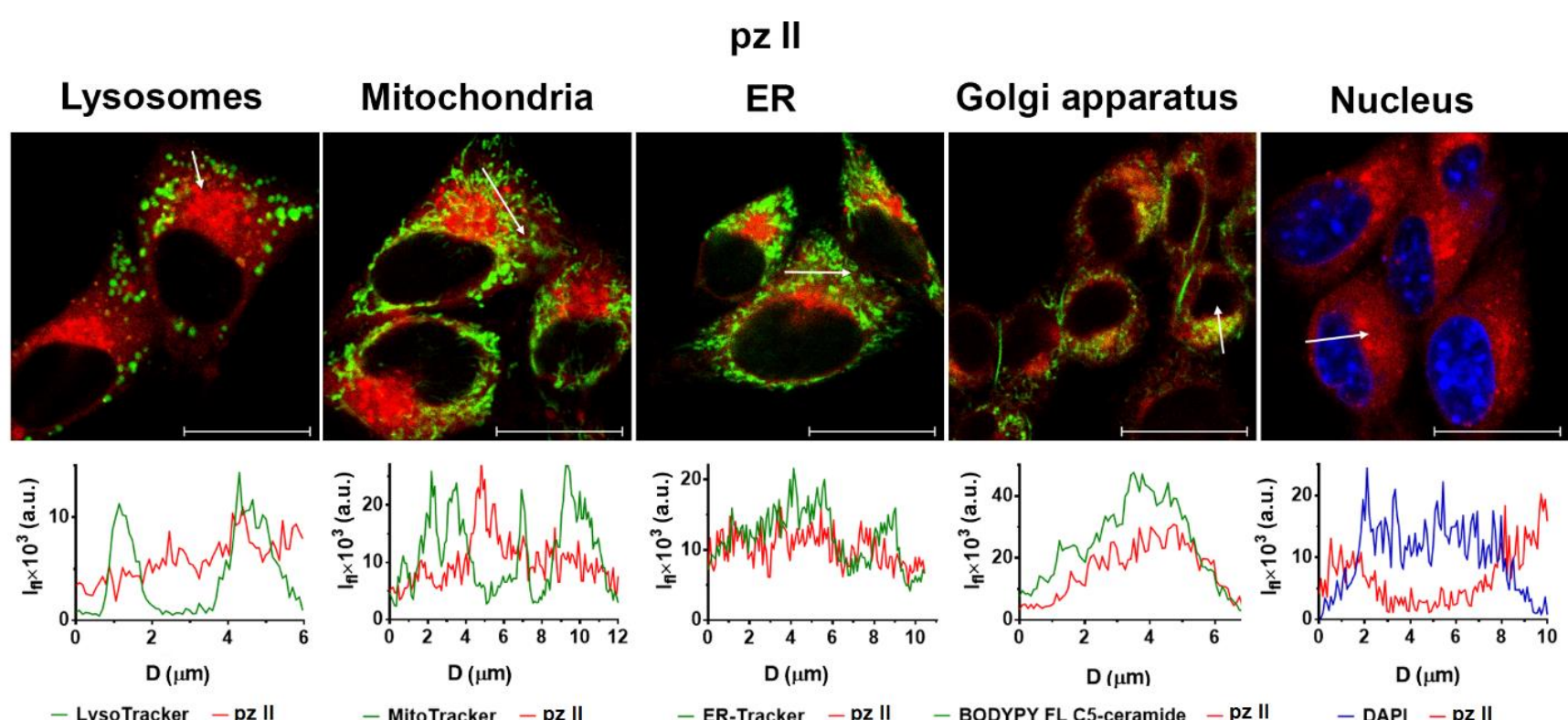

- MitoTracker - pz II

- ER-Tracker - pz II -

pz IV

ER

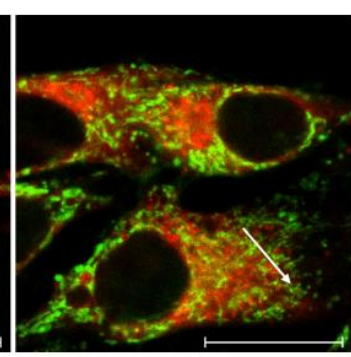

Golgi apparatus

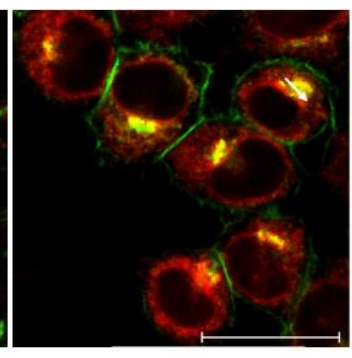

Nucleus
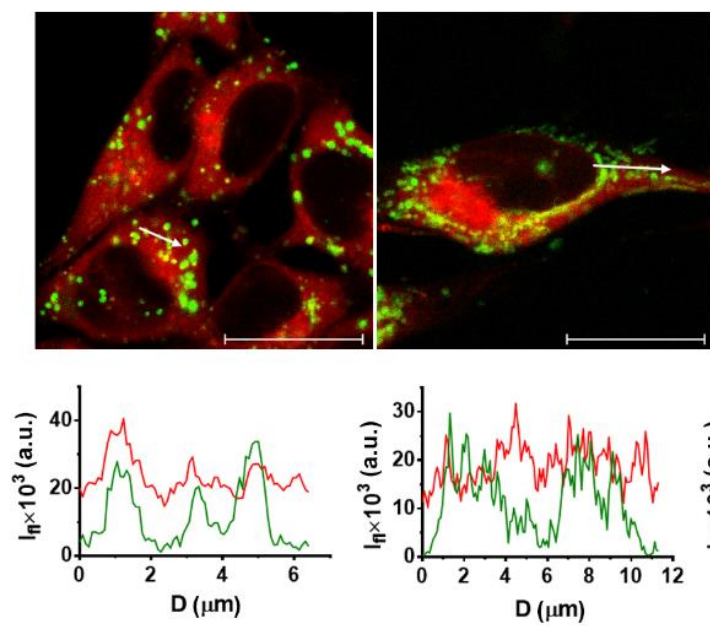

- LysoTracker - pz IV

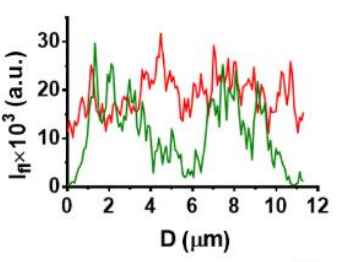

- MitoTracker - pz IV
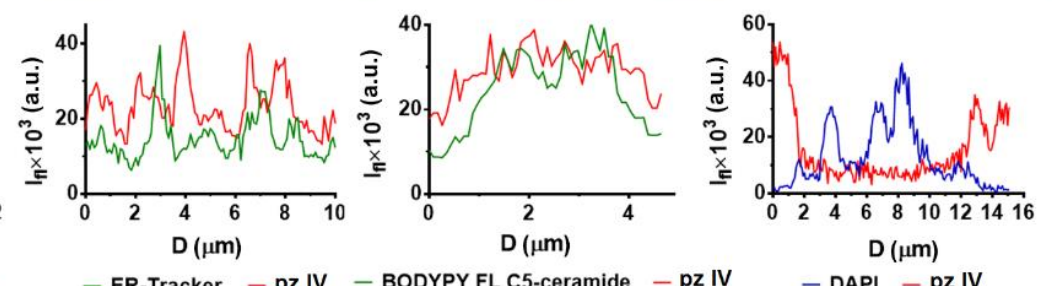

Figure 8. A subcellular distribution of pz II and pz IV in the glioma GL261 cells. Glioma cells were incubated with $10 \mu \mathrm{M}$ pz for $4 \mathrm{~h}$. The following dyes were used for staining of the organelles: LysoTracker Green for lysosomes; MitoTracker Green for mitochondria; ER-Tracker for ER; DAPI for nucleus. The plots present the profiles of the fluorescence signal ( $\mathrm{I}_{\mathrm{fl}}$ ) of the $\mathbf{p z}$ (red line) and organelle dye (green and blue line) along the white arrow indicated in the corresponding image. Scale bar, $20 \mu \mathrm{m}$. 
Exposure to $\mathbf{p z}$ II and $\mathbf{p z}$ IV in the dark led to a reduction in the viability of cancer cells only in concentrations of about $2 \times 10^{-5} \mathrm{M}$. Under light irradiation, both compounds demonstrated light dose-dependent photodynamic activity (Figure S3 from Supplementary Materials). Under a dose of $20 \mathrm{~J} / \mathrm{cm}^{2}$, this was manifested in a significant $(>50 \%)$ loss of cancer cell viability when they were treated with sub-micromolar pz concentrations (Figure 9). Glioma cells are shown to be relatively more sensitive to the pz-based PDT treatment: $\mathrm{IC}_{50}$ values towards GL261 were 0.19 and $0.37 \mu \mathrm{M}$ for $\mathbf{p z ~ I I}$ and $\mathbf{p z ~ I V}$; in the case of carcinoma A431 cells, the values were 0.35 and $0.42 \mu \mathrm{M}$, respectively. The photodynamic index (the ratio of $\mathrm{IC}_{50}$ in the dark and under irradiation) was more than 50, which is an excellent reason to call $\mathbf{p z ~ I I ~ a n d ~} \mathbf{p z ~ I V ~ p o t e n t ~}$ photosensitizers.

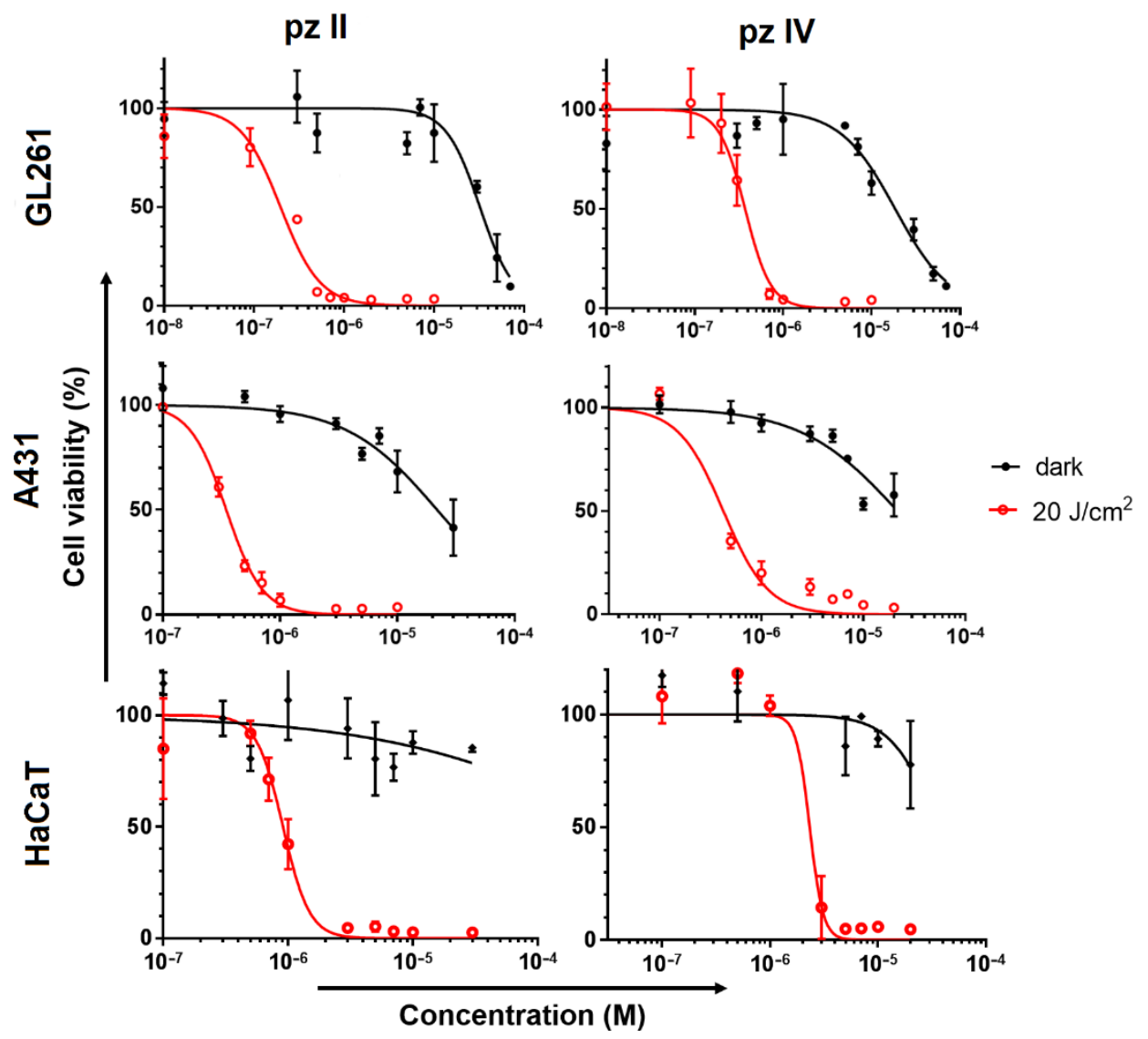

Figure 9. Dark toxicity and photodynamic activity of pz II and pz IV against murine glioma GL261, human epidermoid carcinoma A431 and human keratinocytes HaCaT cells. The cells were incubated with pz in serum-free medium for $4 \mathrm{~h}$ and then exposed to light irradiation $\left(\lambda_{\mathrm{ex}} 615-635 \mathrm{~nm}\right.$, $20 \mathrm{~J} / \mathrm{cm}^{2}$ ) or stayed in the dark for the same time interval. After $24 \mathrm{~h}$, the cell viability was analyzed by MTT assay. The representative dose-response curves from three independent experiments (each in triplicate) are shown. The data represent the mean values $\pm \operatorname{SD}(n=3)$.

Of interest, the photoinduced toxicity of pz II and pz IV against normal keratinocytes was significantly lower than against cancerous skin cells, contrary to the relative $\mathbf{p z}$ accumulation shown above: $\mathrm{IC}_{50}$ values towards $\mathrm{HaCaT}$ were 0.9 and $2.3 \mu \mathrm{M}$, respectively. These values indicate that there is no strict correlation between $\mathrm{pz}$ accumulation and its cytotoxic activity. The peculiarities of redox metabolism and antioxidant pool in cancer cells can result in their high sensitivity to PDT treatment.

\subsection{Intracellular Viscosity Sensing during PDT Treatment with $p z$ II and $p z I V$}

The most intriguing question was whether we can detect intracellular viscosity using pz II and pz IV sensor properties and if we can register PDT-induced viscosity changes. We performed a series of experiments using fluorescence lifetime imaging microscopy 
(FLIM) to answer this question. The fluorescence lifetime of $\mathbf{p z}$ was estimated in intact cells; then, one-half of the microscopic field was treated with an intense laser to induce PDT response. The FLIM images of the whole field were obtained immediately after and at different time points after PDT. The described approach allowed us to take into account unavoidable cell irradiation during the imaging procedure; the cells in the non-treated area serve as a control for analysis of the results.

pz II and pz IV demonstrated a fluorescence lifetime distribution in cells with maxima at $\sim 470$ and $\sim 1250$ ps (Figure 10). It is necessary to underline that the intracellular environment fundamentally differs from a glycerol-ethanol solution; therefore, it is not relevant to apply the described above results to calculate intracellular viscosity. The hydrophobicity of the local microenvironment and the interactions of $\mathbf{p z}$ with intracellular proteins, lipids, nucleic acids, and supramolecular complexes are of the utmost importance. In any case, the registered fluorescence lifetimes evidence the strong hindrance of intramolecular movement in both compounds.

\section{pz II}

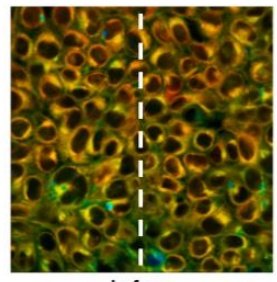

before

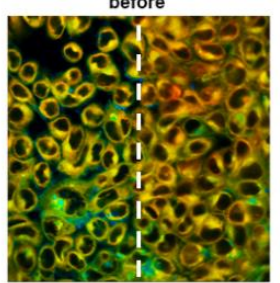

$30 \mathrm{~min}$

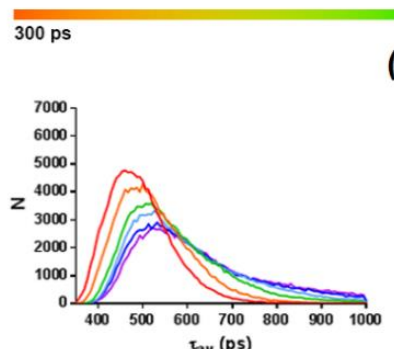

(a2)

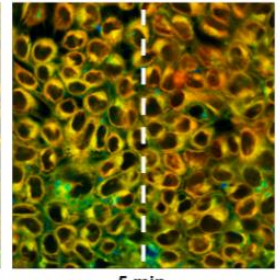

5 min

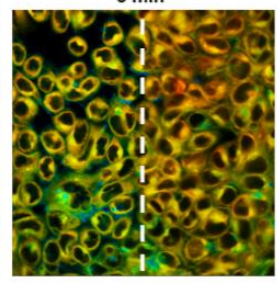

$45 \mathrm{~min}$

(a1)

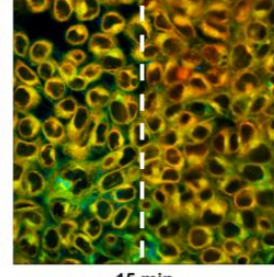

$15 \mathrm{~min}$

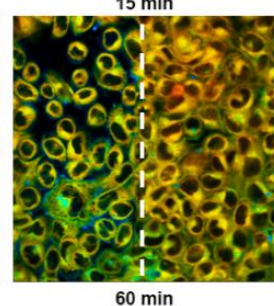

$60 \mathrm{~min}$

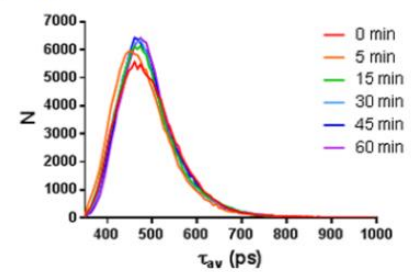

(a3)

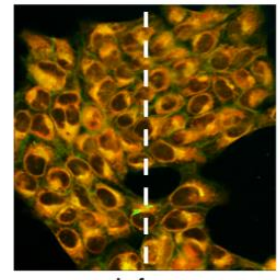

before

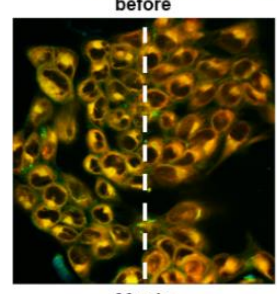

$30 \mathrm{~min}$

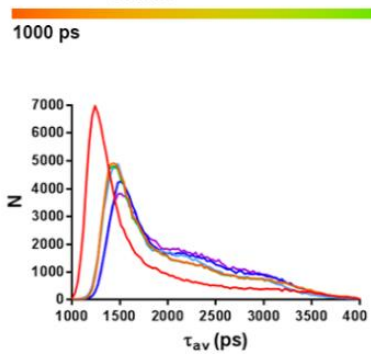

(b2) pz IV
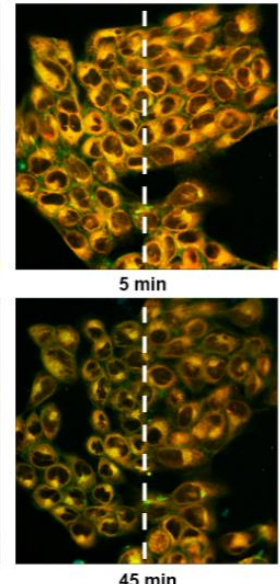

$45 \mathrm{~min}$
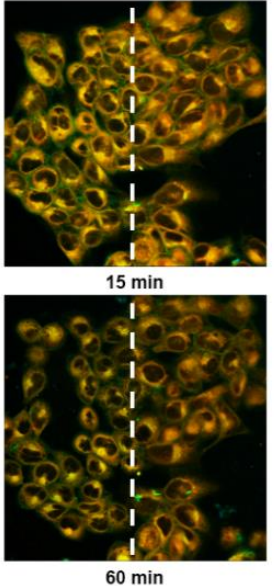

$60 \mathrm{~min}$

(b1)

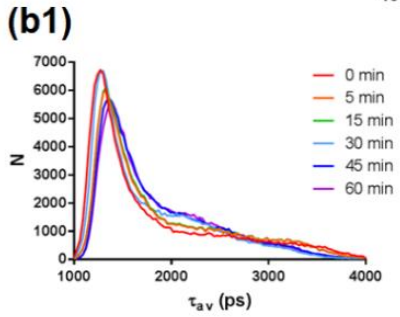

(b3)

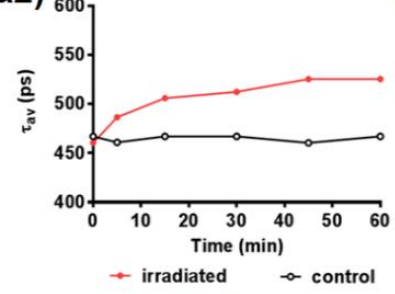

(a4)

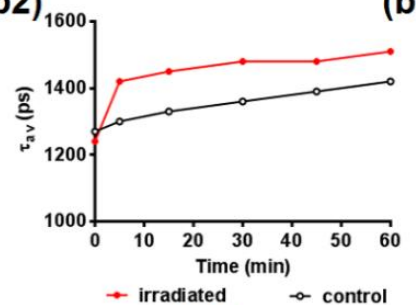

(b4)

Figure 10. Representative FLIM images illustrating pz II's (a1) and pz IV's (b1) fluorescence lifetime ( $\left.\tau_{\mathrm{av}}\right)$ distribution in human epidermoid carcinoma A431 cells before and at different time points after PDT treatment. Photodynamic exposure $\left(594 \mathrm{~nm}, 20 \mathrm{~J} / \mathrm{cm}^{2}\right)$ was performed in the left half of the field of view; irradiated and control areas are divided by a white dotted line. $\lambda_{\mathrm{ex}}, 800 \mathrm{~nm}, \lambda_{\mathrm{em}}, 652-740 \mathrm{~nm}$. The color scale range is between 300 and $1000 \mathrm{ps}$ for pz II and 1000 and $4000 \mathrm{ps}$ for pz IV. Image size, $212 \times 212 \mu \mathrm{m}$. The distribution histograms of a fluorescence lifetime $\left(\tau_{\mathrm{av}}\right)$ in irradiated and control regions for pz II $(\mathbf{a} 2, \mathbf{a} 3)$ and pz IV (b2,b3) and the plot of $\tau_{\mathrm{av}}$ vs. time after irradiation $(\mathbf{a} 4, \mathbf{b} 4)$ are shown. 
PDT treatment induced a shift towards longer pz lifetimes in the irradiated area. This starts immediately after a short period of irradiation and continues during $1 \mathrm{~h}$ of observation (Figure 9). In the case of pz II, this shift was observed from 470 to 525 ps; for pz IV, this shift was from 1250 to 1500 ps. In the latter case, we should note the pronounced changes in the control area in the shown example, presumably due to the cell irradiation during the imaging procedure. Such changes or their absence were detected randomly and seemingly depended on a moderate variation in the initial physiological state of the cell culture. Thus, the viscosity sensitivity of $\mathbf{p z}$ fluorescence provided us with a tool to visualize changes in intracellular viscosity, namely its increase, induced by PDT.

\section{Discussion}

Photodynamic therapy has been used in clinical practice since the middle of the 20th century; by now, it has become widely used in cancer treatment. Over several decades, a substantial amount of experimental and clinical data has been accumulated, which allowed the development of a list of requirements for the photosensitizers used. Among them, the most significant are: (1) photosensitizers should have a constant chemical composition and simple synthesis; (2) they should accumulate quickly and selectively in tumor cells, providing a stable and high quantum yield of singlet oxygen in PDT with subsequent induction of cell death; (3) they should have a minimal cytotoxic effect on normal (non-transformed) cells [30-32]. Despite significant efforts, no "ideal" photosensitizers have been created to date, and plenty of novel photoactive dyes are tested as potential photosensitizers every year. Moreover, new findings in the mechanisms of tumor eradication during PDT, tumor immunity, and overall drug development dictate the need to expand the requirements applied to photosensitizers and revise the concept of an "ideal photosensitizer".

In the current study, we present two tetracyanotetra(aryl)porphyrazines, pz II and pz IV, that efficiently induce photodynamic death on murine glioma GL261 and human epidermoid carcinoma A431 cells. Pz II demonstrates a lower rate of cellular uptake (Figure 7) but slightly higher toxicity against cancer cells (Figure 9). However, the value of the photodynamic index at more than 50 when irradiated at a dose of $20 \mathrm{~J} / \mathrm{cm}^{2}$ supports the high potency of both compounds as photosensitizers.

The advantage of pz II and pz IV compared to clinically approved "classic" photosensitizers is their sensor properties. The molecular rotors' photophysical properties of pz II and pz IV drastically change depending on the viscosity of the surrounding medium. In a less viscous medium, the excitation of the pz molecule is followed by the intramolecular twisting or rotation of side aryl groups, resulting in a very high constant of non-radiative relaxation (Figure 6) and subsequently a low quantum yield (Figure 4) and fluorescence lifetime (Figure 5). In high-viscosity media, intramolecular rotation is inhibited. Thus, we register an increase in the emission intensity and the fluorescence lifetime by several orders of magnitude (Figures 4 and 5). The sensitivity of the fluorescence lifetime is of particular interest, since it can be measured in a complex biological media when no data on the precise concentration of the sensor are available.

It has been reported that the cell response to PDT treatment is accompanied by an increase in intracellular viscosity $[20,33,34]$. We registered the same cell reaction using pz II and pz IV as photosensitizers and, at the same time, viscosity sensors. Higher viscosity can intensify lipid peroxidation in membranes, leading to lipid-to-lipid and lipid-to-protein cross-linking through Schiff base formation [35]. The second important factor is an accumulation of misfolded and partially denatured proteins [36]. This is seemingly the most potent factor influencing the surrounding environment of ER-located porphyrazines during the development of ER stress. In any case, viscosity changes start immediately after the beginning of the PDT treatment and indicate the physiological state of the irradiated cells.

The use of $\mathbf{p z}$ in combination with time-resolved microscopy allowed for obtaining viscosity maps (microviscosity) of cancer cells with submicron resolution and visualizing PDT-driven viscosity changes at the subcellular level (Figure 10). The idea to use cyanoarylporphyrazines to follow viscosity changes during PDT was firstly presented 
for fluorophenyl derivative [20]. In the present work, we described two porphyrazines with several benefits over previously published compounds: a red shift of absorption and emission maxima that is important for future in vivo application; higher PDT activity against cancer cells and large photodynamic index; and low toxicity against neuronal cells [25], which allows pz IV and especially pz II application for treatment of gliomas. We assume that real-time assessment of fluorescence lifetime of $\mathbf{p z ~ I I ~ a n d ~ p z ~ I V ~ p r o v i d e s ~ a ~}$ possibility for light dosimetry and correction of the irradiation regimen. Thus, an absence of pronounced "viscosity" response during irradiation points toward the insufficient intensity of treatment, and vice versa, a fast and robust response indicates the substantial impairment of irradiated cells. Looking ahead, fluorescence lifetime measurement can be the rational basis for the individualization of the PDT treatment. In this case, the estimation of individual responsivity to PDT treatment can be used for light-dose optimization to reach the highest treatment efficacy without severe damage to surrounding normal tissues.

Maintaining a low toxicity effect for normal tissues in the organism is one of the essential requirements for photosensitizers. Our previous in vitro studies showed that pz II and pz IV had a light and mild cytotoxic effect, respectively, for primary neuronal cultures, which are among the most sensitive cells to any physicochemical stimuli and stress [25], which shows good promise for the future in vivo application of both of these compounds. In the present study, we have shown lower photoinduced toxicity of pz II and pz IV against normal keratinocytes compared to skin cancer cells.

A strategy of targeted PDT has been proposed to minimize the side effects mediated by the cytotoxicity to normal cells, representing third-generation photosensitizers. A photoactive chromophore is combined with a targeting moiety or vehicle (i.e., liposomal forms, nanocarriers, conjugates with sugar molecules, monoclonal antibodies, or peptides) that significantly improves the pharmacokinetics of the photosensitizer and allows the reduction in the total administered dose [1,37-39]. We previously demonstrated that other compounds of tetracyanotetra(aryl)porphyrazine group could be efficiently loaded into polymer brush nanoparticles $[40,41]$. Notably, the developed nanocarriers had less dark toxicity than the photosensitizer itself. Another example is the loading of tetracyanotetra(aryl)porphyrazines into liposomes [42]. Thus, in addition to their low toxicity, pz II and pz IV can be encapsulated in a nano-sized vehicle for improvement of the targeted delivery to the tumor tissue via an enhanced permeability and retention effect.

One of the newly established requirements for an "ideal" photosensitizer is the induction of a regulated cell death modality with immunogenic properties. This requirement is descended from uncovering the mechanisms of the interaction of dying/dead cancer cells with immune cells and establishing this interaction as a crucial factor of cancer treatment efficiency. Immunogenic cell death (ICD) has an adjuvant-like effect mediated by the release of damage-associated molecular patterns (DAMPs) responsible for the recruitment and maturation of antigen-presenting cells followed by the induction of T-cell adaptive anticancer immunity and tumor cells eradication [1,43-45]. The ability of photosensitizers to induce ICD is closely linked with their localization in cells [1,45]. Pz II and pz IV accumulate in ER (Figure 8), which might indicate their ability to induce ER-stress during PDT, one of the main prerequisites of ICD induction $[9,45]$. The power of these particular compounds to induce ICD needs to be further investigated; however, we can now assert that tetracyanotetra(aryl)porphyrazines fulfill this requirement. In our previous study, we showed that cancer cells subjected to PDT with two compounds of cyanoarylporphyrazine group with 9-phenanthrenyl and 4-(4-fluorobenzyoxy)phenyl substituted in the aryl frame of the macrocycle demonstrate typical features of ICD: release of crucial DAMPs (e.g., ATP and HMGB1), which induce activation and maturation of dendritic cells in vitro [11]. Moreover, cancer cells stimulated with pz-PDT served as a potent vaccine in a prophylactic tumor vaccination model in vivo, activating the adaptive immune system, thereby ensuring effective protection of mice from tumor growth after challenge with the viable cancer cells.

To sum up, our studies reveal that pz II and pz IV could be considered as potent agents for PDT with high viscosity sensitivity of their photophysical properties. The latter benefit 
feature allowed for visualizing the PDT-driven rise in intracellular viscosity. We assumed that the unique properties of $\mathbf{p z}$ II and $\mathbf{p z}$ IV provide the basis for dosimetry-assisted photodynamic cancer treatment.

\section{Materials and Methods}

\subsection{Analysis of Spectral Properties and Fluorescence Quantum Yield}

The absorption and fluorescence spectra of $\mathbf{p z}$ II and pz IV were registered using a Synergy MX spectrophotometer-spectrofluorometer (BioTek, Winooski, VT, USA). Pz solutions were measured in deionized water and ethanol-glycerol mixtures with a percentage of glycerin from 20 to $100 \%$ at a pz concentration of $5 \mu \mathrm{M}$. The absorption spectra were recorded in the wavelength range of $300-700 \mathrm{~nm}$. The fluorescence spectra were registered in the range of $600-850 \mathrm{~nm}$ with excitation at $580 \mathrm{~nm}$.

The fluorescence quantum yield was determined relative to rhodamine B (SigmaAldrich, Darmstadt, Germany) in water (0.31) [46].

Photobleaching was analyzed in pz solutions in the ethanol-glycerol mixture (1:1) in the concentration of $10 \mu \mathrm{M}$. In this process, $100 \mu \mathrm{L}$ of the solution was placed in a well of the 96-well plate at room temperature and irradiated using a LED light source for microplates $\left(\lambda_{\text {ex }} 615-635 \mathrm{~nm}, 20 \mathrm{~mW} / \mathrm{cm}^{2}\right)$ [47]. Before and after obtaining different doses of irradiation, the fluorescence spectrum of the $\mathbf{p z}$ in solution was registered in the range of 590-800 nm with excitation at $570 \mathrm{~nm}$ using a Synergy MX microplate reader (BioTek, USA).

\subsection{Fluorescence Lifetime Registration}

The fluorescence lifetime of pz II and pz IV in ethanol-glycerol solutions was measured according to the previously developed protocol described in [21]. Fluorescence was excited by a SC-450 laser picosecond pulsed source (Fianium Ltd., Southampton, UK) equipped with band-pass interference filters (ChromaTech., Michigan, USA) to select the wavelength range of $580-595 \mathrm{~nm}$. The signal was detected in the spectral range of $640-700 \mathrm{~nm}$ by detector connected with time-correlated single-photon counting (TCSPC) system (Becker\&Hickl, GmbH, Berlin, Germany). The acquisition time window of the TCSPC system was 0-50 ns, with 1024 channels.

The recorded fluorescence decay curves were deconvoluted using an instrument response function (IRF) recorded as the signal from homogeneous highly scattering non-fluorescent medium. Then, the decay curves were subjected to biexponential fitting, and the intensityweighted average fluorescence lifetime $\left(\tau_{\mathrm{av}}\right)$ was calculated using the following equation:

$$
\tau_{\mathrm{av}}=\frac{\sum_{i} a_{i} \tau_{i}^{2}}{\sum_{i} a_{i} \tau_{i}},
$$

where $i=1,2$, and $a_{i}$ and $\tau_{i}$ are the amplitudes and lifetimes of biexponential fitting components for fluorescence decay curve, respectively. The calculations were performed using SPCImage software (Becker\&Hickl, GmbH).

To confirm that $\mathbf{p z}$ II and $\mathbf{p z}$ IV belong to the group of molecular rotors, we calculated the rate constants of radiative $k_{r}$ and non-radiative $k_{n r}$ relaxation of the excited state:

$$
\varphi=\frac{k_{r}}{\left(k_{r}+k_{n r}\right)}
$$

\subsection{Cell Lines}

Murine glioma GL261, human epidermoid carcinoma A431 and human immortalized keratinocytes $\mathrm{HaCaT}$ were cultured at $37{ }^{\circ} \mathrm{C}$ under $5 \% \mathrm{CO}_{2}$ in DMEM (PanEco, Moscow, Russia) containing $2 \mathrm{mM}$ L-glutamine (PanEco, Russia) and 10\% fetal bovine serum (FBS, Thermo Fisher, Waltham, MA, USA). The culture medium for glioma GL261 was additionally supplemented with $4.5 \mathrm{~g} / \mathrm{L}$ glucose (PanEco, Moscow, Russia) and $100 \mu \mathrm{M}$ 
sodium pyruvate (Thermo Fisher, USA). At the end of the exponential growth period, the cells were removed with a trypsin-versene solution (1:3) (PanEko, Russia).

\subsection{Cellular Uptake of Cyanoarylporphyrazines}

For the microscopy, cells were seeded in 96-well glass-bottom plates (Corning, NY, USA) at $8 \times 10^{4}$ cells per well and grown overnight. Then, the medium was changed to a serum-free medium containing pz II or pz IV at a concentration of $10 \mu \mathrm{M}$ and the cells were incubated for 2 or $4 \mathrm{~h}$. Cells were imaged without changing the medium using an Axio Observer Z1 LSM-710 DUO NLO (Carl Zeiss, Oberkochen, Germany) laser scanning confocal microscope equipped with C-Apochromat $63 \times$ water immersion objective lens with numerical aperture 1.2. Fluorescence was excited at $594 \mathrm{~nm}$ and registered in the range of 600-670 nm. For semiquantitative analysis, the fluorescence intensity of the cytoplasmic region of the cells was measured using ZEN 2012 program; at least 10 cells in two-three fields of view were analyzed.

For the dynamics study, cells were seeded in glass-bottom 96-well plates (Corning, NY, USA) at a density of $10^{4}$ cells per well and allowed to attach overnight. Then, the medium was changed to a serum-free medium containing pz II or pz IV at a concentration of $5 \mu \mathrm{M}$, and the fluorescence signal was registered with a Synergy MX plate reader (BioTek, Winooski, VT, USA) during $300 \mathrm{~min}$. Between the measuring time points, the plate with the cells was kept in $\mathrm{CO}_{2}$ incubator. Fluorescence was excited at a wavelength of $590 \mathrm{~nm}$ and recorded at $650 \mathrm{~nm}$. The registered fluorescence signal was normalized to the maximal value at the end of the incubation to avoid the influence of variations in cell culture density.

\subsection{Subcellular Distribution of Cyanoarylporphyrazines}

The cells were seeded in glass-bottomed 96-well plates (Corning, NY, USA) at a density of $10^{4}$ cells per well and were grown overnight. Then, the culture medium was changed to a serum-free medium containing pz II or pz IV at a concentration of $10 \mu \mathrm{M}$, and the cells were incubated for $4 \mathrm{~h}$.

For colocalization analysis, the following dyes were added to the medium $30 \mathrm{~min}$ before the end of the incubation period according to the manufacturer's instructions (Thermo Fisher, USA): $0.5 \mu \mathrm{M}$ LysoTracker green DND-26 for lysosomes, $0.5 \mu \mathrm{M}$ ER-Tracker for endoplasmic reticulum, $0.5 \mu \mathrm{M}$ MitoTracker Green FM for mitochondria, $3 \mu \mathrm{M}$ DAPI for nuclei, and $5 \mu \mathrm{M}$ BODIPY FL C5-ceramide complexed to BSA for Golgi apparatus. Then, the medium containing $\mathrm{pz}$ and the organelle dye was replaced with a fresh serum-free medium.

Cell images were acquired using an Axio Observer Z1 LSM-710 DUO NLO laser scanning microscope (Carl Zeiss, Germany) with an LD C-Apochromat water immersion objective lens $40 \times / 1.1$. The following regimens were applied: $\lambda_{\mathrm{ex}} 594 \mathrm{~nm}$ and $\lambda_{\mathrm{em}} 630-670 \mathrm{~nm}$ for $\mathbf{p z ~ I I}$ and pz IV; $\lambda_{\text {ex }} 405 \mathrm{~nm}$ and $\lambda_{\mathrm{em}} 420-550 \mathrm{~nm}$ for DAPI; $\lambda_{\mathrm{ex}} 488 \mathrm{~nm}$ and $\lambda_{\mathrm{em}} 500-550 \mathrm{~nm}$ for other organelle dyes.

\subsection{Analysis of Dark Toxicity and Photodynamic Activity of Porphyrazines}

Cells were seeded in a 96-well plate at a density of $6 \times 10^{3}$ cells per well for glioma GL261, $4 \times 10^{3}$ cells per well for carcinoma A431, and $5 \times 10^{3}$ cells per well for human immortalized keratinocytes $\mathrm{HaCaT}$ and were grown overnight. Then, the medium was replaced to a serum-free medium containing $\mathbf{p z ~ I I ~ o r ~} \mathbf{p z}$ IV at concentrations ranging from 0.001 to $70 \mu \mathrm{M}$. After $4 \mathrm{~h}$ of incubation, the medium was replaced with a porphyrazines-free complete culture medium.

For photodynamic activity estimation, the cells were exposed to light irradiation at the dose of $20 \mathrm{~J} / \mathrm{cm}^{2}$ using a LED light source $\left(\lambda_{\text {ex }} 615-635 \mathrm{~nm}, 20 \mathrm{~mW} / \mathrm{cm}^{2}\right)$ [47]. For dark toxicity estimation, cells loaded with pz II or pz IV were handled outside of the $\mathrm{CO}_{2}$ incubator in the dark for an equal time period. The cells without addition of $\mathrm{pz}$ to the medium served as a control.

The MTT test was performed $24 \mathrm{~h}$ after cell irradiation; the medium was exchanged with a fresh one with the addition of $0.5 \mathrm{mg} / \mathrm{mL}$ MTT-reagent (Alfa Aesar, Lancashire, UK), and 
the cells were incubated for $4 \mathrm{~h}$. Then, the medium was aspirated, and formed formazan crystals were dissolved in $200 \mu \mathrm{L}$ of DMSO (PanEco, Russia), and the optical density of the solution was measured at $570 \mathrm{~nm}$ using a Synergy MX microplate reader (BioTek, USA). The relative cell viability was calculated as the percentage of mean optical density in the wells with treated cells to the mean optical density in the wells with control cells.

The half-maximal inhibiting concentrations $\left(\mathrm{IC}_{50}\right)$ were calculated from the resulting dose-effect dependences fitted with a four-parameter model for a lognormal distribution using GraphPad Prism (v.6.0) using the equation:

$$
\mathrm{V}=\mathrm{V}_{\min }+\frac{\mathrm{V}_{\max }-\mathrm{V}}{1+10^{\left(\lg \left(\mathrm{IC}_{50}\right)-\mathrm{C}\right) \cdot \mathrm{SF}}}
$$

where Vmax and Vmin are maximal and minimal viability (V) values, respectively; $\mathrm{C}$ is the concentration; and SF is the slope factor.

\subsection{Fluorescence-Lifetime Imaging Microscopy}

Cells were seeded in $35 \mathrm{~mm}$ glass-bottom Petri dishes (Eppendorf, Hamburg, Germany) at the density of $3 \times 10^{5}$ cells per dish and were grown overnight. Then, the medium was exchanged to a complete culture medium containing pz II or pz IV at a concentration of $5 \mu \mathrm{M}$ and incubated for $4 \mathrm{~h}$. Then, the dish with cell culture was placed on a microscope stage without medium replacement; the microscopy experiments were carried out at $37^{\circ} \mathrm{C}$ and in an atmosphere of $5 \% \mathrm{CO}_{2}$.

Images were acquired using an Axio Observer Z1 LSM-710 DUO NLO laser scanning microscopy system with a FLIM module (Becker\&Hickl, GmbH, Berlin, Germany) using two-photon excitation at a wavelength of $800 \mathrm{~nm}$ and registration of the fluorescence signal in the range of $640-710 \mathrm{~nm}$. At least 0.25 billion photons were collected for every image.

The obtained fluorescence decay curves in every pixel of the images were processed using the SPCImage software (Becker\&Hickl, $\mathrm{GmbH}$ ) and fitted by biexponential decay curve with calculation of the intensity weighted mean lifetime $\tau_{\mathrm{av}}$ using Equation (3).

For photodynamic treatment, $\frac{1}{2}$ of the field of view was exposed to intensive irradiation with a $594 \mathrm{~nm}$ laser at a dose of $10 \mathrm{~J} / \mathrm{cm}^{2}$. FLIM images were acquired before and at different time points after irradiation, and the distribution of $\tau_{a v}$ values in irradiated and non-irradiated control areas was analyzed.

\section{Conclusions}

We present two photo-active dyes of the tetracyanotetra(aryl)porphyrazine group, pz II and pz IV, that combine the properties of potent photosensitizers with viscosity sensors. The compounds have the potential to become beneficial agents for the photodynamic treatment of cancer due to providing the tool for the real-time assessment of tumor cell response directly in the course or immediately after the light irradiation of sensitized tissue. The PDT treatment causes an increase in intracellular viscosity registered by a rise in fluorescence lifetime of $\mathbf{p z}$ II and $\mathbf{p z}$ IV. The rise reflects tumor cell impairment and can be used as an objective criterion for light dosimetry.

We anticipate that the low level of dark toxicity and high photodynamic activity are combined with $\mathbf{p z}$ ability to induce immunogenic cell death, previously shown for two compounds of a similar chemical structure. This property has to be proven in subsequent studies. If this is the case, pz II and pz IV can be considered as potential photodynamic agents for dosimetry-assisted photodynamic cancer treatment.

Supplementary Materials: The following are available online, Figure S1: Photobleaching of pz II and pz IV in ethanol-glycerol solution with $30 \mathrm{cP}$ viscosity. Figure S2: Fluorescence decay curves of pz II and pz IV in ethanol/glycerol mixtures of different viscosity. Figure S3: Dose-dependent photodynamic activity of pz II and pz IV against murine glioma GL261 and human epidermoid carcinoma A431 cells. 
Author Contributions: Conceptualization-I.V.B., L.G.K., M.V.V. and D.V.K.; Methodology-I.V.B., T.A.M., N.Y.S., V.I.P. and L.G.K.; Validation-I.V.B., N.Y.S., V.I.P., N.N.P., V.D.T., T.A.M., S.A.L. and L.G.K.; Formal analysis-T.A.M., V.D.T., N.N.P., S.A.L. and N.Y.S.; Investigation-T.A.M., V.D.T., N.N.P., S.A.L., N.Y.S. and V.I.P.; Data curation -I.V.B., T.A.M., V.D.T., N.N.P., S.A.L. and N.Y.S.; Writing-original draft-I.V.B., T.A.M., N.Y.S., N.N.P.; Writing—review and editing-L.G.K., M.V.V. and D.V.K.; Supervision-L.G.K., M.V.V. and D.V.K.; Project administration-M.V.V. and D.V.K.; Resources-M.V.V. and D.V.K.; Funding acquisition-M.V.V. and D.V.K. All authors have read and agreed to the published version of the manuscript.

Funding: The study was supported by a grant from Russian Science Foundation (RSF, project no.18-15-00279 https: / /rscf.ru/en/project/18-15-00279/ (accessed on 13 July 2021)). Porphyrazine synthesis was carried out within the state assignment of the Ministry of Science and Higher Education of the Russian Federation (project No. 0729-2020-0061).

Institutional Review Board Statement: Not applicable.

Informed Consent Statement: Not applicable.

Data Availability Statement: The data used to support the findings of this study are available from the corresponding author upon request.

Conflicts of Interest: The authors declare no conflict of interest.

Sample Availability: Samples of the compounds are available from the authors.

\section{References}

1. Alzeibak, R.; Mishchenko, T.A.; Shilyagina, N.Y.; Balalaeva, I.V.; Vedunova, M.V.; Krysko, D.V. Targeting immunogenic cancer cell death by photodynamic therapy: Past, present and future. J. Immunother. Cancer 2021, 9, e001926. [CrossRef] [PubMed]

2. Hamblin, M.R. Photodynamic Therapy for Cancer: What's Past is Prologue. Photochem. Photobiol. 2020, 96, 506-516. [CrossRef] [PubMed]

3. Mishchenko, T.A.; Balalaeva, I.V.; Vedunova, M.V.; Krysko, D.V. Ferroptosis and Photodynamic Therapy Synergism: Enhancing Anticancer Treatment. Trends Cancer 2021, 7, 484-487. [CrossRef]

4. Castano, A.P.; Demidova, T.N.; Hamblin, M.R. Mechanisms in photodynamic therapy: Part one-photosensitizers, photochemistry and cellular localization. Photodiagnosis Photodyn. Ther. 2004, 1, 279-293. [CrossRef]

5. Horne, T.K.; Cronjé, M.J. Mechanistics and photo-energetics of macrocycles and photodynamic therapy: An overview of aspects to consider for research. Chem. Biol. Drug Des. 2017, 89, 221-242. [CrossRef]

6. Plaetzer, K.; Krammer, B.; Berlanda, J.; Berr, F.; Kiesslich, T. Photophysics and photochemistry of photodynamic therapy: Fundamental aspects. Lasers Med. Sci. 2009, 24, 259-268. [CrossRef]

7. Henderson, B.W.; Bellnier, D.A. Tissue localization of photosensitizers and the mechanism of photodynamic tissue destruction. Ciba Found. Symp. 1989, 146, 112-125. [PubMed]

8. Kwiatkowski, S.; Knap, B.; Przystupski, D.; Saczko, J.; Kędzierska, E.; Knap-Czop, K.; Kotlińska, J.; Michel, O.; Kotowski, K.; Kulbacka, J. Photodynamic therapy-Mechanisms, photosensitizers and combinations. Biomed. Pharmacother. 2018, 106, 1098-1107. [CrossRef] [PubMed]

9. Deng, H.; Zhou, Z.; Yang, W.; Lin, L.S.; Wang, S.; Niu, G.; Song, J.; Chen, X. Endoplasmic Reticulum Targeting to Amplify Immunogenic Cell Death for Cancer Immunotherapy. Nano Lett. 2020, 20, 1928-1933. [CrossRef] [PubMed]

10. Turubanova, V.D.; Balalaeva, I.V.; Mishchenko, T.A.; Catanzaro, E.; Alzeibak, R.; Peskova, N.N.; Efimova, I.; Bachert, C.; Mitroshina, E.V.; Krysko, O.; et al. Immunogenic cell death induced by a new photodynamic therapy based on photosens and photodithazine. J. Immunother. Cancer 2019, 7, 019-0826. [CrossRef]

11. Turubanova, V.D.; Mishchenko, T.A.; Balalaeva, I.V.; Efimova, I.; Peskova, N.N.; Klapshina, L.G.; Lermontova, S.A.; Bachert, C.; Krysko, O.; Vedunova, M.V.; et al. Novel porphyrazine-based photodynamic anti-cancer therapy induces immunogenic cell death. Sci. Rep. 2021, 11, 021-86354. [CrossRef]

12. Doix, B.; Trempolec, N.; Riant, O.; Feron, O. Low Photosensitizer Dose and Early Radiotherapy Enhance Antitumor Immune Response of Photodynamic Therapy-Based Dendritic Cell Vaccination. Front. Oncol. 2019, 9, 811. [CrossRef] [PubMed]

13. Wilson, B.C.; Patterson, M.S. The physics, biophysics and technology of photodynamic therapy. Phys. Med. Biol. 2008, 53, R61. [CrossRef] [PubMed]

14. Gouirand, V.; Guillaumond, F.; Vasseur, S. Influence of the Tumor Microenvironment on Cancer Cells Metabolic Reprogramming. Front. Oncol. 2018, 8, 117. [CrossRef] [PubMed]

15. Li, S.; Meng, W.; Guan, Z.; Guo, Y.; Han, X. The hypoxia-related signaling pathways of vasculogenic mimicry in tumor treatment. Biomed. Pharmacother. 2016, 80, 127-135. [CrossRef] [PubMed]

16. Borgia, F.; Giuffrida, R.; Caradonna, E.; Vaccaro, M.; Guarneri, F.; Cannavò, S.P. Early and Late Onset Side Effects of Photodynamic Therapy. Biomedicines 2018, 6, 12. [CrossRef] [PubMed] 
17. van Straten, D.; Mashayekhi, V.; de Bruijn, H.S.; Oliveira, S.; Robinson, D.J. Oncologic Photodynamic Therapy: Basic Principles, Current Clinical Status and Future Directions. Cancers 2017, 9, 19. [CrossRef]

18. Hanahan, D.; Weinberg, R.A. Hallmarks of cancer: The next generation. Cell 2011, 144, 646-674. [CrossRef] [PubMed]

19. Krysko, O.; Aaes, T.L.; Kagan, V.E.; D’Herde, K.; Bachert, C.; Leybaert, L.; Vandenabeele, P.; Krysko, D.V. Necroptotic cell death in anti-cancer therapy. Immunol. Rev. 2017, 280, 207-219. [CrossRef]

20. Izquierdo, M.A.; Vyšniauskas, A.; Lermontova, S.A.; Grigoryev, I.S.; Shilyagina, N.Y.; Balalaeva, I.V.; Klapshina, L.G.; Kuimova, M.K. Dual use of porphyrazines as sensitizers and viscosity markers in photodynamic therapy. J. Mater. Chem. B 2015, 3 , 1089-1096. [CrossRef]

21. Lermontova, S.; Grigoryev, I.; Peskova, N.; Ladilina, E.; Lyubova, T.; Plekhanov, V.; Grishin, I.; Balalaeva, I.; Klapshina, L. Cyano-Aryl Porphyrazine Pigments with Polycyclic Substituents as the Promising Agents for Photodynamic Therapy and Potential Sensors of Local Viscosity. Macroheterocycles 2019, 12, 268-275. [CrossRef]

22. Lermontova, S.A.; Grigor'ev, I.S.; Ladilina, E.Y.; Balalaeva, I.V.; Shilyagina, N.Y.; Klapshina, L.G. Porphyrazine Structures with Electron-Withdrawing Substituents as the Base for Materials for Photonics and Biomedicine. Russ. J. Coord. Chem. 2018, 44, 301-315. [CrossRef]

23. Lermontova, S.A.; Grigoryev, I.S.; Shilyagina, N.Y.; Peskova, N.N.; Balalaeva, I.V.; Shirmanova, M.V.; Klapshina, L.G. New porphyrazine macrocycles with high viscosity-sensitive fluorescence parameters. Russ. J. Gen. Chem. 2016, 86, 1330-1338. [CrossRef]

24. Lermontova, S.A.; Lyubova, T.S.; Ladilina, E.Y.; Plekhanov, V.I.; Balalaeva, I.V.; Boyarskii, V.P.; Klapshina, L.G. New Cyanoarylporphyrazines with High Sensitivity of Photophysical Parameters to Viscosity as Promising Agents for Photodynamic Therapy. Russ. J. Gen. Chem. 2020, 90, 249-256. [CrossRef]

25. Mishchenko, T.A.; Turubanova, V.D.; Mitroshina, E.V.; Alzeibak, R.; Peskova, N.N.; Lermontova, S.A.; Klapshina, L.G.; Balalaeva, I.V.; Vedunova, M.V.; Krysko, D.V. Effect of novel porphyrazine photosensitizers on normal and tumor brain cells. J. Biophotonics 2020, 13, 17. [CrossRef] [PubMed]

26. Klapshina, L.G.; Grigoryev, I.S.; Douglas, W.E.; Trifonov, A.A.; Gudilenkov, I.D.; Semenov, V.V.; Bushuk, B.A.; Bushuk, S.B. Metal template assembly of highly functionalized octacyanoporphyrazine framework from TCNE structural units. Chem. Commun. 2007, 1942-1944. [CrossRef]

27. Haidekker, M.A.; Theodorakis, E.A. Molecular rotors-fluorescent biosensors for viscosity and flow. Org. Biomol. Chem. 2007, 5, 1669-1678. [CrossRef] [PubMed]

28. Kuimova, M.K. Mapping viscosity in cells using molecular rotors. Phys. Chem. Chem. Phys. 2012, 14, 12671-12686. [CrossRef]

29. Yoon, H.J.; Dakanali, M.; Lichlyter, D.; Chang, W.M.; Nguyen, K.A.; Nipper, M.E.; Haidekker, M.A.; Theodorakis, E.A. Synthesis and evaluation of self-calibrating ratiometric viscosity sensors. Org. Biomol. Chem. 2011, 9, 3530-3540. [CrossRef]

30. Jori, G. Tumour photosensitizers: Approaches to enhance the selectivity and efficiency of photodynamic therapy. J. Photochem. Photobiol. B 1996, 36, 87-93. [CrossRef]

31. Moan, J. Properties for optimal PDT sensitizers. J. Photochem. Photobiol. B 1990, 5, 521-524. [CrossRef]

32. Penning, L.C.; Dubbelman, T.M. Fundamentals of photodynamic therapy: Cellular and biochemical aspects. Anticancer Drugs 1994, 5, 139-146. [CrossRef]

33. Kuimova, M.K.; Botchway, S.W.; Parker, A.W.; Balaz, M.; Collins, H.A.; Anderson, H.L.; Suhling, K.; Ogilby, P.R. Imaging intracellular viscosity of a single cell during photoinduced cell death. Nat. Chem. 2009, 1,69-73. [CrossRef]

34. Vyšniauskas, A.; Qurashi, M.; Kuimova, M.K. A Molecular Rotor that Measures Dynamic Changes of Lipid Bilayer Viscosity Caused by Oxidative Stress. Chemistry 2016, 22, 13210-13217. [CrossRef] [PubMed]

35. Gaschler, M.M.; Stockwell, B.R. Lipid peroxidation in cell death. Biochem. Biophys. Res. Commun. 2017, 482, 419-425. [CrossRef] [PubMed]

36. Moserova, I.; Kralova, J. Role of ER stress response in photodynamic therapy: ROS generated in different subcellular compartments trigger diverse cell death pathways. PLoS ONE 2012, 7, e32972. [CrossRef] [PubMed]

37. Kutova, O.M.; Guryev, E.L.; Sokolova, E.A.; Alzeibak, R.; Balalaeva, I.V. Targeted Delivery to Tumors: Multidirectional Strategies to Improve Treatment Efficiency. Cancers 2019, 11, 68. [CrossRef] [PubMed]

38. Lan, M.; Zhao, S.; Liu, W.; Lee, C.S.; Zhang, W.; Wang, P. Photosensitizers for Photodynamic Therapy. Adv. Healthc. Mater. 2019, 8, e1900132. [CrossRef] [PubMed]

39. Yang, M.; Li, J.; Gu, P.; Fan, X. The application of nanoparticles in cancer immunotherapy: Targeting tumor microenvironment. Bioact. Mater. 2020, 6, 1973-1987. [CrossRef]

40. Bauman, M.; Yakimansky, A.; Meleshko, T.; Ilgach, D.; Anan'eva, T.; Klapshina, L.; Lermontova, S.; Balalaeva, I.; Douglas, W. Novel Regular Polyimide-graft-(Polymethacrylic Acid) Brushes: Synthesis and Possible Applications as Nanocontainers of Cyanoporphyrazine Agents for Photodynamic Therapy. J. Polym. Sci. Part A Polym. Chem. 2013, 51, 4267-4281.

41. Shilyagina, N.Y.; Peskova, N.N.; Lermontova, S.A.; Brilkina, A.A.; Vodeneev, V.A.; Yakimansky, A.V.; Klapshina, L.G.; Balalaeva, I.V. Effective delivery of porphyrazine photosensitizers to cancer cells by polymer brush nanocontainers. J. Biophotonics 2017, 10, 1189-1197. [CrossRef]

42. Yudintsev, A.V.; Shilyagina, N.Y.; Dyakova, D.V.; Lermontova, S.A.; Klapshina, L.G.; Guryev, E.L.; Balalaeva, I.V.; Vodeneev, V.A. Liposomal Form of Tetra(Aryl)Tetracyanoporphyrazine: Physical Properties and Photodynamic Activity In Vitro. J. Fluoresc. 2018, 28, 513-522. [CrossRef] [PubMed] 
43. Ahmed, A.; Tait, S.W.G. Targeting immunogenic cell death in cancer. Mol. Oncol. 2020, 14, 2994-3006. [CrossRef] [PubMed]

44. Galluzzi, L.; Vitale, I.; Warren, S.; Adjemian, S.; Agostinis, P.; Martinez, A.B.; Chan, T.A.; Coukos, G.; Demaria, S.; Deutsch, E.; et al. Consensus guidelines for the definition, detection and interpretation of immunogenic cell death. J. Immunother. Cancer 2020, 8 , e000337. [CrossRef] [PubMed]

45. Krysko, D.V.; Garg, A.D.; Kaczmarek, A.; Krysko, O.; Agostinis, P.; Vandenabeele, P. Immunogenic cell death and DAMPs in cancer therapy. Nat. Rev. Cancer 2012, 12, 860-875. [CrossRef] [PubMed]

46. Kubin, R.F.; Fletcher, A.N. Fluorescence quantum yields of some rhodamine dyes. J. Lumin. 1982, 27, 455-462. [CrossRef]

47. Shilyagina, N.Y.; Plekhanov, V.I.; Shkunov, I.V.; Shilyagin, P.A.; Dubasova, L.V.; Brilkina, A.A.; Sokolova, E.A.; Turchin, I.V.; Balalaeva, I.V. LED Light Source for in vitro Study of Photosensitizing Agents for Photodynamic Therapy. Sovrem. Tehnol. V Med. 2014, 6, 15-22. 